ARTICLE

DOI: $10.1038 / s 41467-017-02272-y$

\title{
Deregulated PP1 $\alpha$ phosphatase activity towards MAPK activation is antagonized by a tumor suppressive failsafe mechanism
}

Ming Chen ${ }^{1}$, Lixin Wann ${ }^{2,3}$, Jiangwen Zhang ${ }^{4}$, Jinfang Zhang ${ }^{2}$, Lourdes Mendez ${ }^{1}$, John G. Clohessy ${ }^{1}$, Kelsey Berry ${ }^{1}$, Joshua Victor ${ }^{1}$, Qing Yin ${ }^{3}$, Yuan Zhu², Wenyi Wei ${ }^{2}$ \& Pier Paolo Pandolfi (i) ${ }^{1}$

The mitogen-activated protein kinase (MAPK) pathway is frequently aberrantly activated in advanced cancers, including metastatic prostate cancer ( $\mathrm{CaP}$ ). However, activating mutations or gene rearrangements among MAPK signaling components, such as Ras and Raf, are not always observed in cancers with hyperactivated MAPK. The mechanisms underlying MAPK activation in these cancers remain largely elusive. Here we discover that genomic amplification of the PPP1CA gene is highly enriched in metastatic human CaP. We further identify an S6K/PP1 $\alpha / B-R a f$ signaling pathway leading to activation of MAPK signaling that is antagonized by the PML tumor suppressor. Mechanistically, we find that PP1 $\alpha$ acts as a B-Raf activating phosphatase and that PML suppresses MAPK activation by sequestering PP1 $\alpha$ into PML nuclear bodies, hence repressing S6K-dependent PP1 $\alpha$ phosphorylation, 14-3-3 binding and cytoplasmic accumulation. Our findings therefore reveal a PP1 $\alpha / P M L$ molecular network that is genetically altered in human cancer towards aberrant MAPK activation, with important therapeutic implications.

\footnotetext{
${ }^{1}$ Cancer Research Institute, Beth Israel Deaconess Cancer Center, Department of Medicine and Pathology, Beth Israel Deaconess Medical Center, Harvard Medical School, Boston, MA 02215, USA. ${ }^{2}$ Department of Pathology, Beth Israel Deaconess Medical Center, Harvard Medical School, Boston, MA 02115, USA. ${ }^{3}$ Department of Molecular Oncology, H. Lee Moffitt Cancer Center and Research Institute, Tampa, FL 33612, USA. ${ }^{4}$ School of Biological Sciences, The University of Hong Kong, Hong Kong 999077, China. Correspondence and requests for materials should be addressed to

P.P.P. (email: ppandolf@bidmc.harvard.edu)
} 
A ctivation of signaling pathways, such as the phosphoinositide-3-kinase (PI3K)/AKT and mitogenactivated protein kinase (MAPK), is regulated by feedback inhibition in both normal and cancer cells ${ }^{1,2}$. Evasion of feedback inhibition or failsafe mechanisms resulting from aberrant activation of major oncogenic pathways represent one of the critical mechanisms underlying tumor progression in tumors of diverse histological origin ${ }^{3,4}$. On the other hand, relief of negative feedback by anticancer drugs constitutes a major hurdle to limit the success of several targeted therapies ${ }^{5}$. Hence, identification of the key pathways that govern such regulation is of utmost importance for tumor-specific therapeutic targets.

Prostate cancer $(\mathrm{CaP})$ is the most common malignancy found in men, and an estimated 1 in 7 men in the United States will be diagnosed with $\mathrm{CaP}$ during their lifetime ${ }^{6}$. In the past 25 years, $\mathrm{CaP}$ mortality has declined by nearly $40 \%$; however, improvement in survival for patients with metastatic disease has not contributed substantially to the observed drop in CaP mortality ${ }^{7}$. More than 26,000 men in the United States die annually of metastatic $\mathrm{CaP}^{6}$. Recent whole-exome sequencing studies have revealed that copy number alterations, recurrent somatic mutations and genomic rearrangements are among the driving forces for metastatic castration-resistant prostate cancer (mCRPC) and have identified distinct molecular subtypes of mCRPC based on alterations in existing signaling pathways ${ }^{8,9}$.

Co-activation of the PI3K/AKT and MAPK pathways is frequently observed in advanced and metastatic $\mathrm{CaP}$ and is found to be associated with disease progression and poor prognosis ${ }^{10}$. One of the dominant mechanisms underlying PI3K/AKT activation is inactivation of PTEN (phosphatase and tensin homolog) ${ }^{11}$. In contrast, the mechanisms underlying MAPK activation, to date, remain largely elusive since activating mutations or gene rearrangements among MAPK signaling components are rare in human $\mathrm{CaP}^{8,12-17}$. Notably, PTEN loss/PI3K-AKT activation occurs as an early event in the development of human $\mathrm{CaP}^{18}$, leading to feedback inhibition on Ras/Raf/MAPK signaling ${ }^{19,20}$ (Supplementary Fig. 1a-b). How human CaP evades this feedback inhibition to frequently co-activate the PI3K/AKT and MAPK signaling is also poorly understood. In view of these critical gaps in the field, we investigated the mechanistic basis of MAPK activation in metastatic human $\mathrm{CaP}$.

Here we report an S6K/PP1 $\alpha / \mathrm{B}$-Raf pathway that activates MAPK signaling in PI3K/AKT-driven cancers and is opposed by the promyelocytic leukemia (PML) tumor suppressor. We further demonstrate its importance in regulating $\mathrm{CaP}$ cell migration and invasion and in metastatic human $\mathrm{CaP}$.

\section{Results}

Amplification of PPP1CA in metastatic human CaP. It is now well recognized that the MAPK cascade is negatively regulated through inhibitory phosphorylation of components of the pathway, in particular, Raf kinases, the major upstream activators of MAPK signaling ${ }^{21-25}$. Raf kinases can not only be switched on by acquiring activating mutations, but also through phosphatasemediated dephosphorylation at their inhibitory sites to relieve inhibition and to allow reactivation $21,22,26,27$. Given that activating mutations in Raf kinases are rare in human $\mathrm{CaP}$, we postulated that aberrant phosphatase activity might promote Raf kinases activity and subsequent MAPK activation in metastatic human CaP.

We focused on PP2A and PP1, two major eukaryotic protein phosphatases that are reported to contribute to $>90 \%$ of serine/ threonine dephosphorylation and regulate a variety of cellular processes through the dephosphorylation of distinct substrates ${ }^{28}$, and we initially sought to determine if genetic alterations to either of these protein phosphatases could help establish a role in the context of metastatic cancer. Interestingly, the catalytic subunit of protein phosphatase $1 \alpha(P P 1 \alpha)$, encoded by the PPP1CA gene in humans, is located on chromosomal band 11q13, one of the regions frequently amplified in comparative genomic hybridization (CGH) analysis of human $\mathrm{CaP}^{29,30}$. Moreover, enhanced cytoplasmic PP1 $\alpha$ immunostaining strongly correlates with high Gleason Score ${ }^{30}$, suggesting that $\mathrm{PP} 1 \alpha$ may be involved in prostate tumorigenesis. To confirm the relevance of $P P P 1 C A$ to human $\mathrm{CaP}$, we evaluated the genomic status of PPP1CA in a recent array-based CGH (aCGH) data set $^{8}$ of 59 localized prostate cancer (LPC) and $35 \mathrm{mCRPC} \mathrm{CaP.} \mathrm{We} \mathrm{found} \mathrm{that} \mathrm{PPP1CA} \mathrm{was}$ amplified in $7 \%$ of LPC and $17 \%$ of mCRPC, respectively (Fig. 1a). To independently validate the findings from the aCGH data set, we analyzed a recent large whole-exome sequencing data set $^{9}$ of 150 samples from mCRPC patients. Consistent with the aCGH analysis, PPP1CA was amplified in $25 \%$ of mCRPC (Fig. 1b). Notably, PPP1CA, which is $\sim 2 \mathrm{Mb}$ away from cyclin D1 a proto-oncogene also associated with metastatic $\mathrm{CaP}^{18}$, was more frequently amplified than cyclin D1 in mCRPC (25\% vs 5\%, Fig. 1c). Also of interest, PPP1CA was co-amplified with cyclin D1 in 5 out of 7 cases where the latter was amplified (Fig. 1c). Thus, amplification of PPP1CA occurs frequently in metastatic human CaP.

PP1 $\alpha$ mediates PML-loss-induced MAPK activation. We previously reported that co-deletion of PTEN and PML leads to MAPK reactivation in mouse prostate epithelial cells and human $\mathrm{CaP}$ cells and frequently occurs in metastatic human $\mathrm{CaP}^{31}$ To determine if PPP1CA genomic amplification could cooperate with
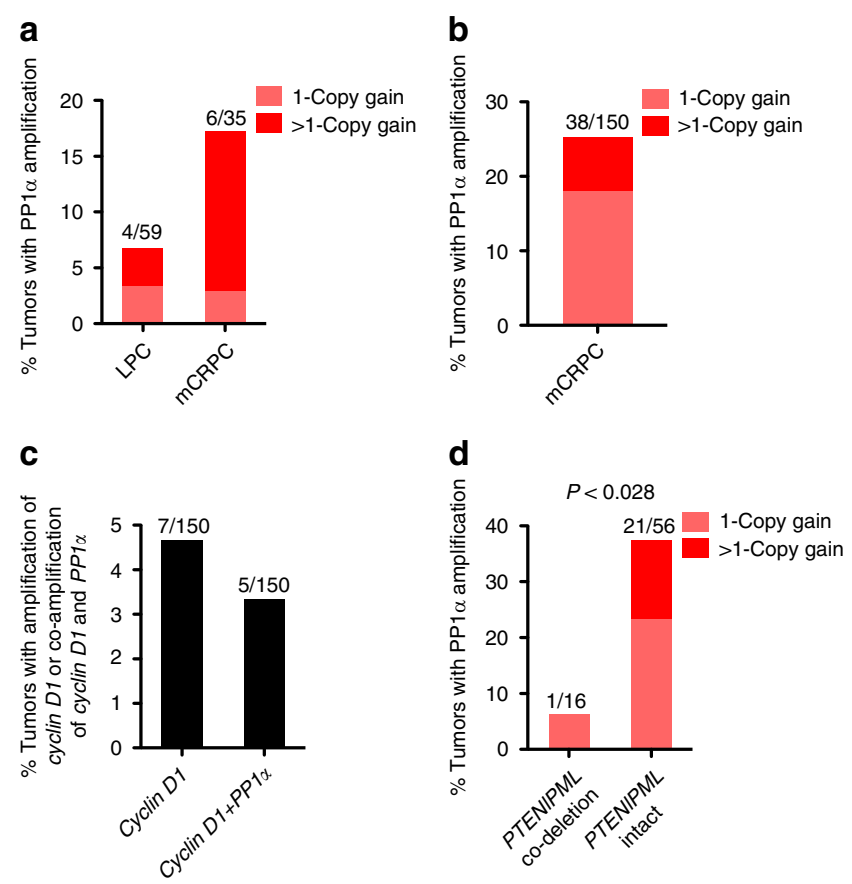

Fig. 1 Amplification of PPP1CA occurs frequently in metastatic human CaP and is often mutually exclusive with co-deletion of PTEN and PML. a, b Bar graph showing the percentage of amplification of PPP1CA in LPC and mCRPC samples from the Grasso et al. ${ }^{8}$ data set (a) and in mCRPC samples from the Robinson et al. ${ }^{9}$ data set (b). c Bar graph showing the percentage of amplification of cyclin D1 alone or together with PPP1CA in mCRPC samples from the Robinson et al. ${ }^{9}$ data set. $\mathbf{d}$ Association between genomic amplification of PPP1CA and co-deletion of PTEN and PML from the Robinson et al. ${ }^{9}$ data set. Data were analyzed by Fisher's exact test, $P<$ 0.05 was considered significant 
co-deletion of PTEN and PML in metastatic human $\mathrm{CaP}$, we determined whether amplification of $P P P 1 C A$ was correlated with co-deletion of PTEN and PML in the Robinson et al. ${ }^{9}$ data set. Strikingly, we found that $P P P 1 C A$ genomic amplification and codeletion of PTEN and PML were often mutually exclusive (Fig. 1d), supporting their proto-oncogenic functions in the same pathway. In keeping with this notion, overexpression of PP1 $\alpha$ induced a marked increase in extracellular signal regulated kinase
(ERK) phosphorylation (Fig. 2a and Supplementary Fig. 2a). Conversely, knockdown of $P P 1 \alpha$ via small interfering RNA (siRNA) attenuated ERK phosphorylation in both LNCaP and PC3 cells (Fig. 2b), suggesting that PP1 $\alpha$ is the principle phosphatase that positively regulates the MAPK signaling pathway. In contrast, although PP2A has previously been identified as the phosphatase mediating the dephosphorylation and reactivation of Raf kinases (Supplementary Fig. $2 \mathrm{~b})^{22}$, the overexpression or

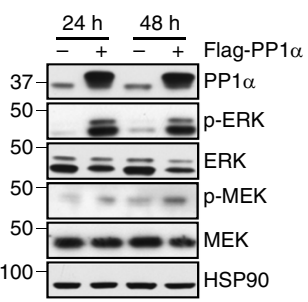

\section{b}

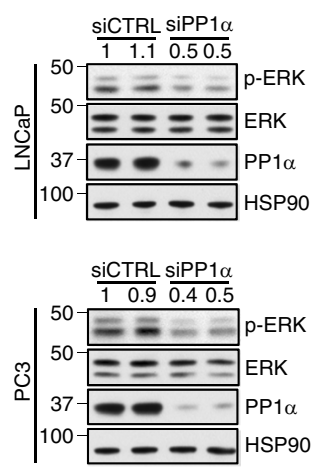

C

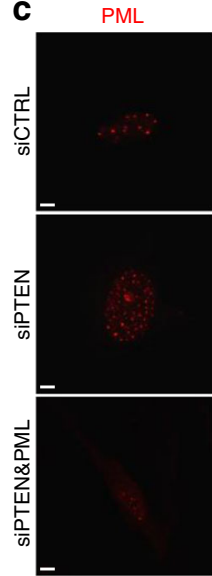

PP10
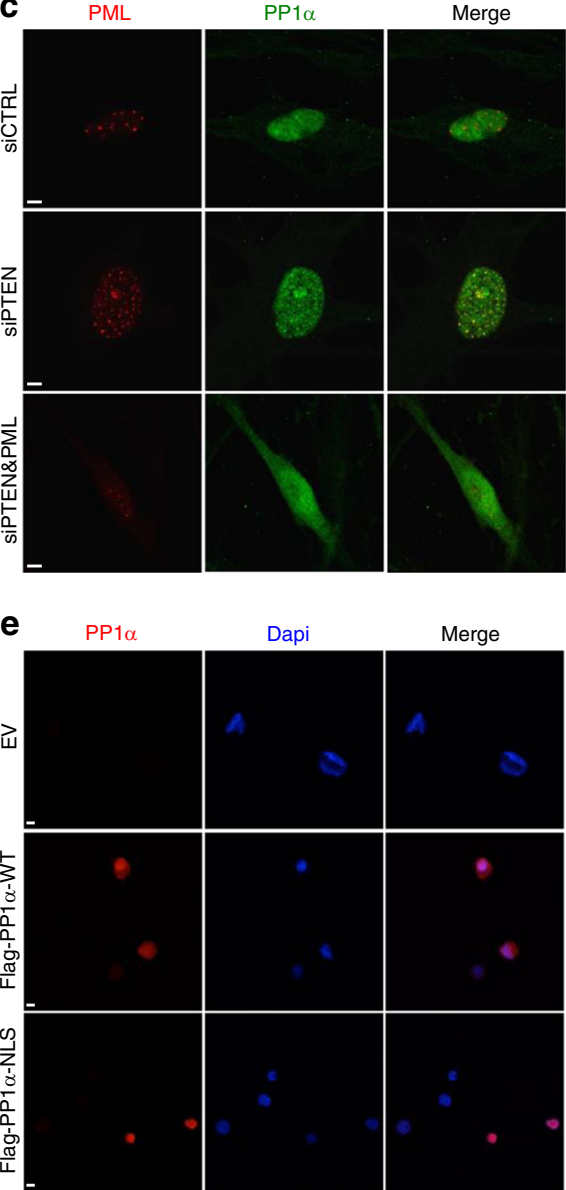

Dapi

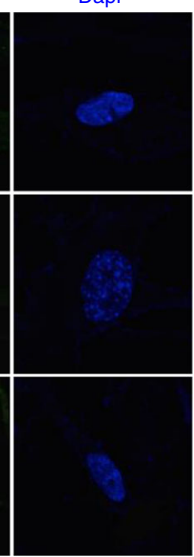

d

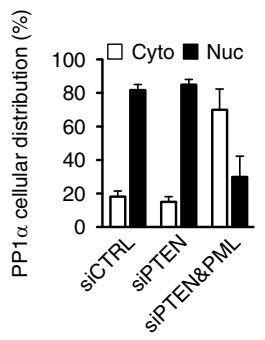

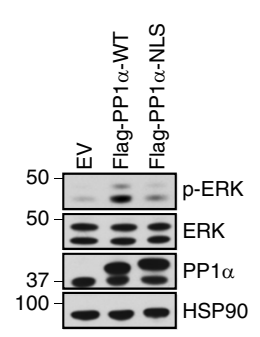

f

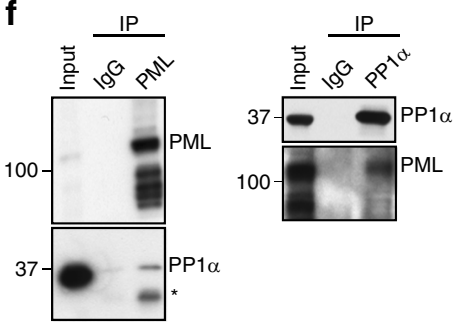

g

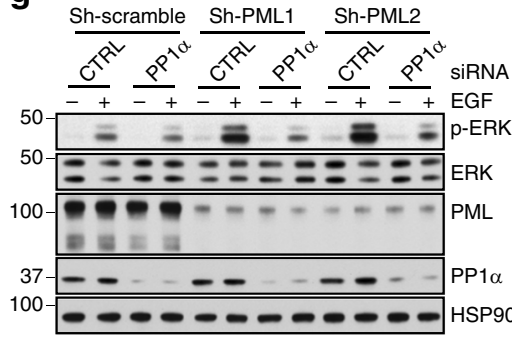

h

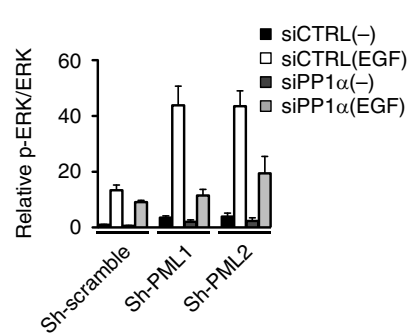

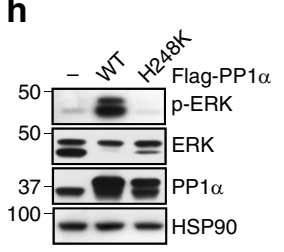

Fig. 2 PP1 $\alpha$ mediates PML-loss-induced MAPK activation. a, b Immunoblot (IB) analysis of lysates from 293T cells transfected with empty vector (EV) or Flag-PP1 $\alpha$ for the indicated times (a), lysates from LNCaP or PC3 cells transfected with control or PP1 $\alpha$ siRNA for $48 \mathrm{~h}$ (b). c, d Immunofluorescence (c) and fractionation (d) of PP1 $\alpha$ protein in WI-38 cells transfected with control, PTEN or PTEN plus PML siRNA for $48 \mathrm{~h}$. Quantification of the percentage of PP1 $\alpha$ protein in the cytosolic and nuclear fraction was carried out with ImageJ software after it was normalized against cytosolic marker HSP90 and nuclear marker Lamin B1, respectively. Data shown are mean \pm s.e.m. of three independent experiments. Scale bar, $5 \mu \mathrm{m}$. e Immunofluorescence and IB analysis of 293T cells transfected with EV, WT or NLS-tagged Flag-PP1 $\alpha$. Scale bar, $5 \mu \mathrm{m}$. f Endogenous reciprocal co-immunoprecipitation of PML and PP1 $\alpha$ in PC3 cells. Input is $10 \%$ of total cell extracts used for immunoprecipitation. ${ }^{\star}$ Indicates a nonspecific band. $\mathbf{g}$ IB analysis of lysates from control or PML stable knocked-down PC3 cells transfected with control or PP1 $\alpha$ siRNA for $48 \mathrm{~h}$, followed by serum-starvation for $4 \mathrm{~h}$ and stimulation with $10 \mathrm{ng} / \mathrm{ml}$ EGF for $5 \mathrm{~min}$. Quantification of $\mathrm{p}$-ERK/ERK levels was carried out with ImageJ software. Numbers indicate the relative ratios to controls for phosphoprotein/total protein. Data shown are mean \pm s.e.m. of three independent experiments. $\mathbf{h}$ IB analysis of lysates from 293T cells transfected with EV, WT or phosphatase-inactive (H248K) Flag-PP1 $\alpha$ for $24 \mathrm{~h}$ 
silencing of the PP2A catalytic subunit (PP2A-C) did not affect ERK phosphorylation in either 293T cells or CaP cell lines (Supplementary Fig. 2c-e), presumably due to its complex effects on various components of the MAPK cascade ${ }^{32}$, and no consistent genomic alterations in PPP2CA, the gene encoding $\mathrm{PP} 2 \mathrm{~A}-\mathrm{C}$ protein, have been found in $\mathrm{mCRPC}$ samples from the Robinson et al. ${ }^{9}$ data set (Supplementary Fig. 2f).

Although co-deletion of $P T E N$ and $P M L$ is often mutually exclusive with amplification of PPP1CA, we did not rule out the possibility that co-loss of PTEN/PML might lead to aberrant PP1 $\alpha$ phosphatase activity, thereby contributing to $P M L$-loss-induced MAPK activation. It is well established that PML is induced upon PTEN inactivation in a p53-dependent and -independent manner ${ }^{4,33,34}$ and that PML, through its nuclear body (NB)dependent scaffold activity, can interact with a variety of proteins, including phosphatases, to regulate their functions ${ }^{35}$. Additionally, $\mathrm{PP} 1 \alpha$ is a known $\mathrm{Rb}$ phosphatase and, like PML, can bind $\mathrm{Rb}$ (Supplementary Fig. $2 \mathrm{~g}$ ) and cooperate with $\mathrm{Rb}$ function in the induction of cellular senescence ${ }^{36}$. We therefore considered that upon PTEN loss, PML might recruit PP1 $\alpha$ into the PML-NBs to promote $P T E N$-loss-induced cellular senescence, a potent failsafe mechanism that restricts tumorigenesis ${ }^{4}$, and simultaneously restrict PP1 $\alpha$-induced MAPK activation. WI-38 human diploid fibroblasts, the well-accepted cell model used to study the senescence with intact PTEN and PML protein expression, were used to test this possibility. We found that acute knockdown of PTEN in WI-38 cells induced senescence, PML upregulation, strong co-localization of PML and PP1 $\alpha$, and suppression of MAPK signaling (Supplementary Fig. $2 \mathrm{~h}$ and Fig. 2c, d). On the other hand, we reasoned that in PTEN/PML double-null cells, due to the lack of sequestration to NBs, PP1 $\alpha$ could contribute to MAPK activation through the dephosphorylation and reactivation of Raf kinases. In support of this hypothesis, the cytoplasmic accumulation of $P P 1 \alpha$ was significantly increased upon simultaneous knockdown of PTEN and PML along with concomitant MAPK reactivation in WI-38 cells (Fig. 2c, d). Moreover, compared to wild-type (WT) PP1 $\alpha$, a PP1 $\alpha$ mutant constitutively targeted to the nucleus by fusing the NLS sequence derived from c$\mathrm{Myc}^{37}$ displayed a drastically decreased capacity to activate ERK (Fig. 2e), further corroborating the role of subcellular compartmentalization in the regulation of $P P 1 \alpha$-induced ERK activation. Importantly, PML and PP1 $\alpha$ interacted with each other in vivo in PTEN-null CaP cells. Immunoprecipitation of PML led to the coimmunoprecipitation of PP1 $\alpha$ and vice versa in PC3 cells (Fig. $2 \mathrm{f}$ ).

To further investigate whether PP1 $\alpha$ might mediate $P M L$-lossdriven MAPK activation, we used siRNA targeting $P P 1 \alpha$ in stable $P M L$ knockdown cells. We found that the induction of basal and EGF-stimulated ERK phosphorylation through stable knockdown of $P M L$ was suppressed by PP1 $\alpha$ downregulation (Fig. 2g). Therefore, $P M L$-loss-driven MAPK activation is mediated, at least in part, by PP1 $\alpha$. Notably, the phosphatase activity of PP1 $\alpha$ is required for MAPK activation since expression of the phosphatase-inactive PP $1 \alpha$ mutant $(\mathrm{H} 248 \mathrm{~K})^{38}$ did not affect ERK phosphorylation (Fig. 2h). In line with this, PC3 cells treated with tautomycin, a more selective inhibitor for $\mathrm{PP} 1 \alpha^{39-42}$, displayed a dose-dependent inhibition of EGF-induced ERK phosphorylation (Supplementary Fig. 2i). Thus, we conclude that in PTEN and PML double-null cells, sequestration of PP1 $\alpha$ to NBs is impaired and in turn facilitates the aberrant cytosolic localization of PP1 $\alpha$ and its subsequent activation of MAPK signaling.

S6K induces PP1a phosphorylation, 14-3-3 binding and cytoplasmic accumulation. To gain further mechanistic insights into how PP1 $\alpha$ is delocalized into the cytoplasm, we examined which
AGC kinase can trigger cytoplasmic accumulation of PP1 $\alpha$ given that the AGC family kinases are commonly activated upon PTEN loss ${ }^{43}$. We found that S6K1, but not other AGC kinases such as AKT and SGK, phosphorylated PP1 $\alpha$ in vivo (Fig. 3a), induced the interaction of PP1 $\alpha$ with 14-3-3 $\gamma$ (Fig. 3b) and led to increased cytoplasmic accumulation of PP1 $\alpha$ (Fig. 3c, d). Notably, knockdown of $S 6 K 1$ via siRNA largely suppressed $P P 1 \alpha$-induced ERK activation (Fig. 3e), suggesting that activation of ERK by $\mathrm{PP} 1 \alpha$ is dependent on S6K. In support of PP1 $\alpha$ being an S6K substrate, we identified two highly conserved imperfect AGC family kinase-recognition motifs (RxRxxp/T) located at S224/ T226 and T320 of PP1 $\alpha$ protein, respectively (Fig. 3f). We generated PP1 $\alpha$ mutants in which S224/T226 (S224A/T226A), T320 (T320A) or all three sites (3A) were mutated to alanine. In vitro kinase assays confirmed that recombinant S6K1 could also phosphorylate PP1 $\alpha$ (Fig. 3g). Moreover, S224A/T226A and 3A PP1 $\alpha$ mutants, but not T320A, displayed drastically reduced S6K1-dependent PP1 $\alpha$ phosphorylation (Fig. 3g). Consequently, S224A/T226A and 3A PP1 $\alpha$ mutants had a lower capacity to interact with 14-3-3 and to activate MAPK signaling (Fig. 3h, i), suggesting that S6K-mediated PP1 $\alpha$ phosphorylation on S224/ T226 is critical for the binding of PP1 $\alpha$ with 14-3-3 and for the ability of PP1 $\alpha$ to activate MAPK.

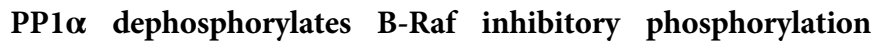
sites. Next, we asked if PP1 $\alpha$ could interact with Raf family kinases. Immunoprecipitation of $\mathrm{PP} 1 \alpha$ revealed a strong and specific interaction between $\mathrm{PP} 1 \alpha$ and B-Raf and to a lesser extent, A-Raf, while PP1 $\alpha$ did not interact with C-Raf or other components of the MAPK cascade, such as MEK and ERK (Fig. 4a, the left panel). Given that A-Raf shows weak interaction with PP1 $\alpha$ and has low intrinsic activity towards MAPK activation ${ }^{44}$, further studies investigating the effect of PP1 $\alpha$ on Raf family kinases were focused on B-Raf. The interaction between $\mathrm{PP} 1 \alpha$ and B-Raf was further confirmed by reciprocal immunoprecipitation in which $\mathrm{PP} 1 \alpha$ co-immunoprecipitated with anti-BRaf precipitates (Fig. 4a, the right panel).

The observation that $\mathrm{PP} 1 \alpha$ and B-Raf interact and that the phosphatase activity of $P P 1 \alpha$ is required for MAPK activation led us to investigate whether B-Raf might be a putative substrate of PP1 $\alpha$. We therefore asked if B-Raf itself is dephosphorylated by PP1 $\alpha$. Since ERK-mediated feedback inhibitory phosphorylation on S151, T401, S750 and T753 of B-Raf protein negatively regulates its kinase activity ${ }^{22}$, we reasoned that $\mathrm{PP} 1 \alpha$ could dephosphorylate these inhibitory sites and, in turn, relieve feedback inhibition and reactivate MAPK. To address whether PP1 $\alpha$ activates B-Raf through these inhibitory sites, we made use of B-Raf protein mutants in which an individual inhibitory site, as well as all four sites (4A), were mutated to alanine. As expected, cells overexpressing either PP1 $\alpha$ or WT B-Raf had higher ERK phosphorylation than cells transfected with empty vector (Fig. 4b). Additionally, cells overexpressing both PP1 $\alpha$ and WT B-Raf displayed even higher ERK phosphorylation (Fig. 4b), suggesting that $\mathrm{PP} 1 \alpha$ can enhance B-Raf activity. On the other hand, the $4 \mathrm{~A}$ B-Raf mutant, but not single alanine B-Raf mutants, displayed an enhanced basal ability to activate MAPK compared to WT B-Raf (Fig. 4b), indicating that these four sites indeed negatively regulate B-Raf activity, while dephosphorylation of a single inhibitory site is not sufficient to increase B-Raf activity. Critically, the $4 \mathrm{~A}$ B-Raf mutant was insensitive to PP1 $\alpha$ activation (Fig. 4b). In contrast, mutation of other known B-Raf inhibitory phosphorylation sites, including S365A/S429A/T440A ${ }^{24}$, S465A/ $S 467 \mathrm{~A}^{25}$ and $\mathrm{S} 614 \mathrm{~A}^{23}$, to alanine failed to blunt PP1 $\alpha$-mediated ERK activation (Supplementary Fig. 2j-1). Therefore, PP1 $\alpha$ appears to exert its effect on B-Raf primarily through the ERKregulated inhibitory sites. 


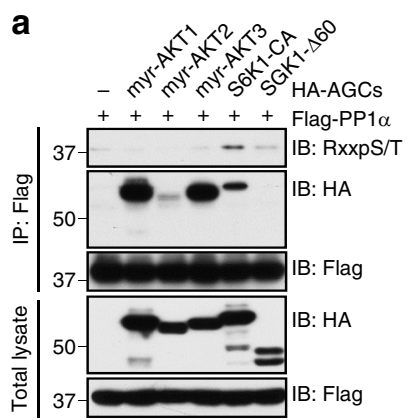

b $\quad-\beta \gamma \varepsilon \quad \sigma \quad \zeta$ HA-14-3-3
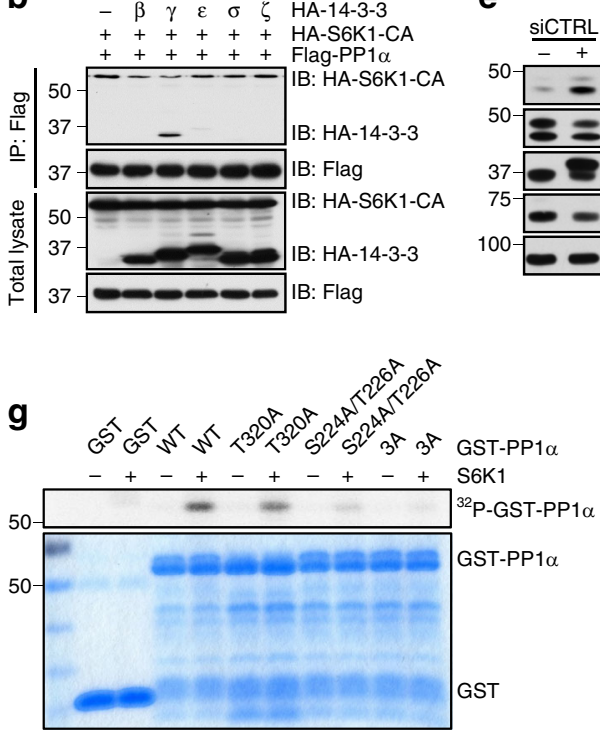

C

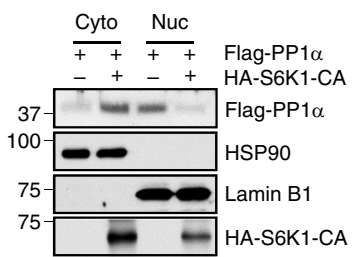

e

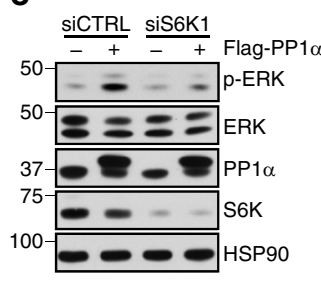

d
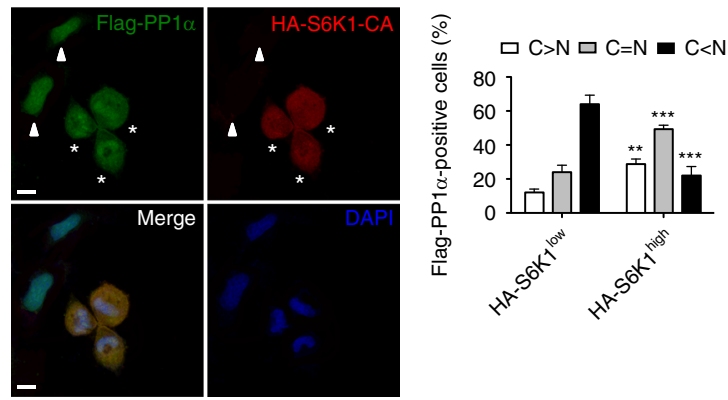

f

Homo sapiens Mus musculus Rattus norvegicus Xenopus laevis Zebra fish

D. melanogaster AGC kinase consensus
217 ENDRGVSFTFGA GENDRGVSFTFGA GENDRGVSFTFGA GENDRGVSFTFGA GENDRGVSFTFGA GENDRGVSFTFGA $\mathrm{RxxS} / \mathrm{T}$
PGGRPITPPR PGGRPITPPR PGGRPITPPR NQSRPVTPPR GSGRPVTPPR SSGRPLTPPR $\mathrm{RxXS} / \mathrm{T}$
$320 \quad 323$

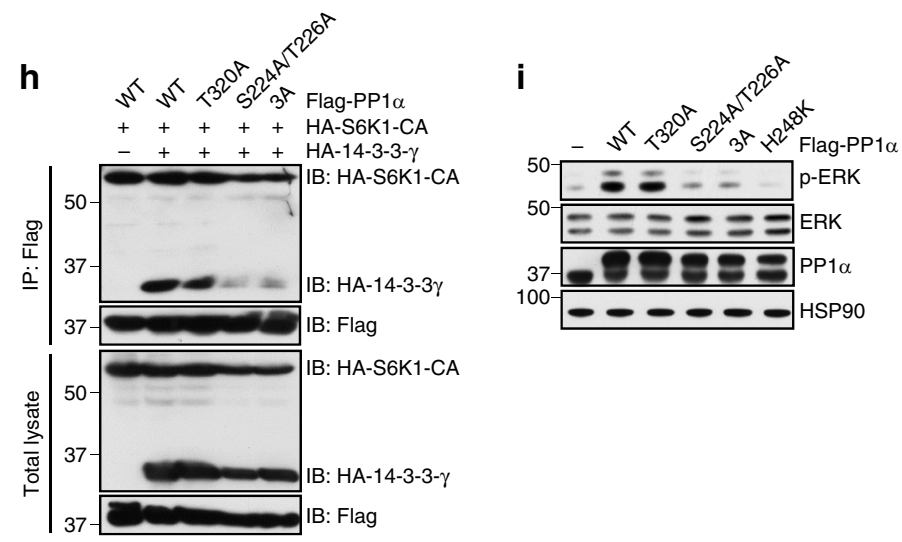

Fig. 3 S6K1 phosphorylates $\mathrm{PP} 1 \alpha$, induces the binding of $\mathrm{PP} 1 \alpha$ with 14-3-3 $\gamma$ and triggers its cytoplasmic accumulation. $\mathbf{a}$, $\mathbf{b}$ IB analysis of total lysates and immunoprecipitates from 293T cells transfected with Flag-PP1 $\alpha$ plus EV or the indicated HA-tagged constitutively active (CA) AGC family kinases for 48 $\mathrm{h}$ (a), from 293T cells transfected with Flag-PP1 $\alpha$, HA-S6K1-CA plus EV or the indicated HA-tagged 14-3-3 isoforms for $48 \mathrm{~h}$ (b). c Fractionation of $293 \mathrm{~T}$ cells transfected with Flag-PP1 $\alpha$ plus EV or HA-S6K1-CA for $48 \mathrm{~h}$. d Immunofluorescence and quantitation of 293T cells transfected with Flag-PP1 $\alpha$ and HA-S6K1-CA for $48 \mathrm{~h}$. Arrowhead, HA-S6K1 ${ }^{\text {low }}$ cells; asterisk, HA-S6K1 ${ }^{\text {high }}$ cells. Data shown are mean \pm s.e.m. of three independent experiments. ${ }^{\star \star} P$ $<0.01,{ }^{\star \star \star} P<0.001$ by unpaired two-tailed $t$-test. Scale bar, $10 \mu \mathrm{m}$. e IB analysis of lysates from 293T cells transfected with control or S6K1 siRNA in the absence and in the presence of Flag-PP1 $\alpha$ for $24 \mathrm{~h}$. f A schematic showing the two highly conserved putative S6K sites, S224/T226 and T320, in PP1 $\alpha$ protein. $\mathbf{g}$ In vitro S6K-mediated PP1 $\alpha$ kinase assays. Bacterial-expressed WT or mutant GST-PP1 $\alpha$ was purified and incubated with S6K1 in the kinase buffer with $\left[\gamma_{-}{ }^{32} \mathrm{P}\right]$ ATP. Reaction was stopped by sample buffer and resolved by SDS-PAGE. $\mathbf{h}, \mathbf{i}$ IB analysis of total lysates and immunoprecipitates from 293T cells transfected with the indicated WT or mutant Flag-PP1 $\alpha$ constructs, HA-S6K1-CA plus EV or HA-14-3-3y for 48 h (h), lysates from 293T cells transfected with EV or the indicated WT or mutant Flag-PP1 $\alpha$ constructs for $24 \mathrm{~h}$ (i)

To determine which site could be dephosphorylated by $\mathrm{PP} 1 \alpha$, we purified GST-3A-B-Raf proteins in which one inhibitory site was WT and the other three sites were mutated to alanine. GST-WT-B-Raf and GST-4A-B-Raf protein were included as the positive and negative control, respectively. We then phosphorylated GST-B-Raf in vitro by incubating B-Raf with recombinant ERK2 protein, and next used the phosphorylated form of B-Raf as a substrate for recombinant PP1 $\alpha$. We confirmed that GST-B-Raf was phosphorylated by ERK2 in vitro ${ }^{22}$, mainly on S151 and T753 (Fig. 4c), and found that PP1 $\alpha$ dephosphorylated B-Raf on both ERK phosphorylation sites (Fig. 4d). Thus, PP1 $\alpha$ appears to dephosphorylate these inhibitory sites of B-Raf, triggering relief of feedback inhibition and consequent activation of the MAPK pathway.
PP1 $\alpha$ promotes CaP cell invasiveness via MAPK signaling. The identification of $P P P 1 C A$ amplification in metastatic human $\mathrm{CaP}$ is consistent with a pro-metastatic role for PPP1CA in the prostate (Fig. 1a, b). We therefore examined whether overexpression of PP1 $\alpha$ affects $\mathrm{CaP}$ cell migration and invasion. Indeed, we found that LNCaP cells stably overexpressing PP1 $\alpha$ exhibited higher ERK activation along with significantly increased cell migration and invasion (Fig. 4e). Notably, treatment with the MEK inhibitor, U0126, in LNCaP cells repressed not only basal but also PP1 $\alpha$-induced cell migration and invasion (Fig. 4e). Similar results were also obtained in PC3 cells (Supplementary Fig. $2 \mathrm{~m}$ ). These functional data, together with the human genetic and mechanistic analyses, implicate PPP1CA as a pro-metastatic proto-oncogene in human $\mathrm{CaP}$ and MAPK signaling as one of the key downstream effectors of PP1 $\alpha$-induced cell invasiveness. 
a

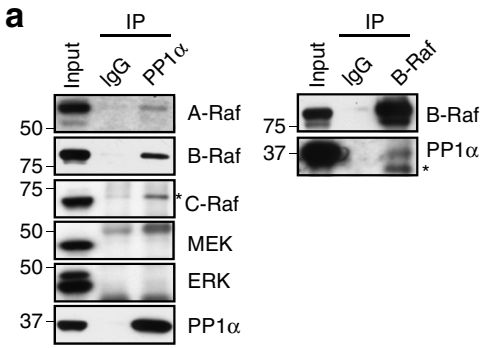

C
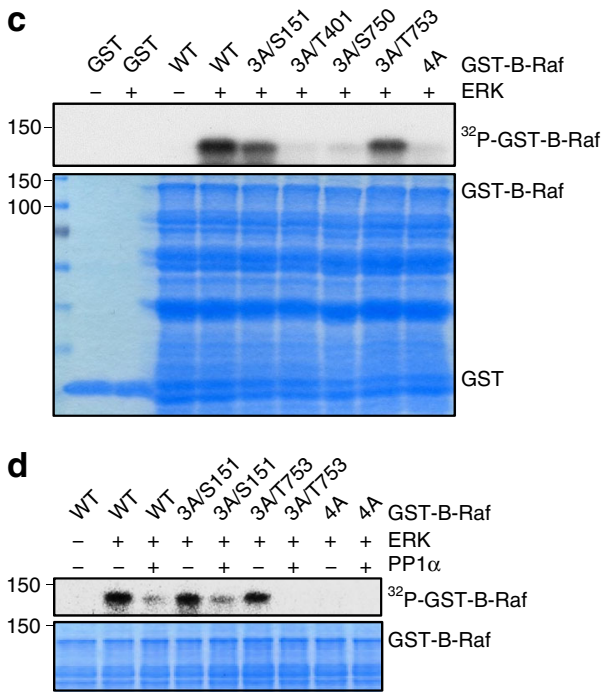

b

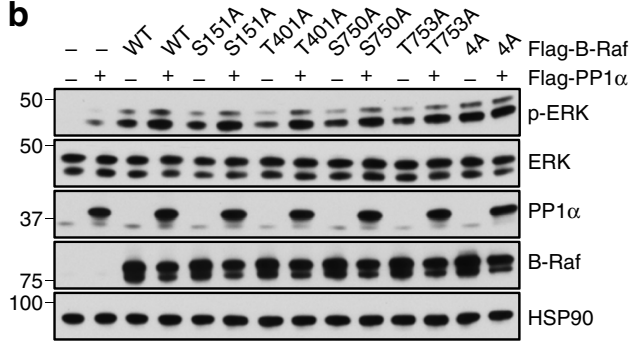

e

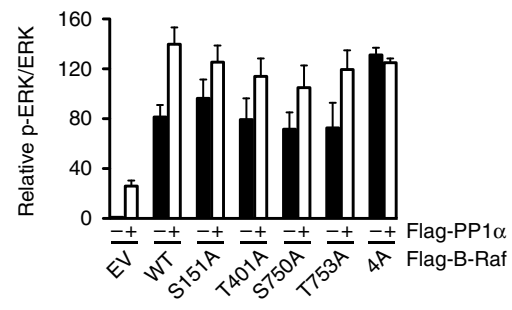

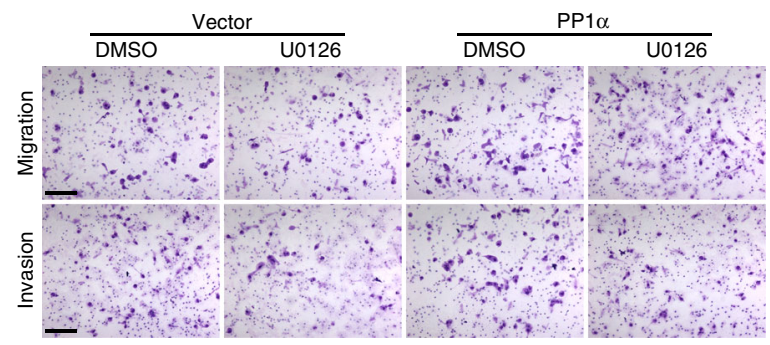

$\mathbf{f}$

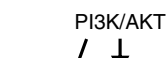

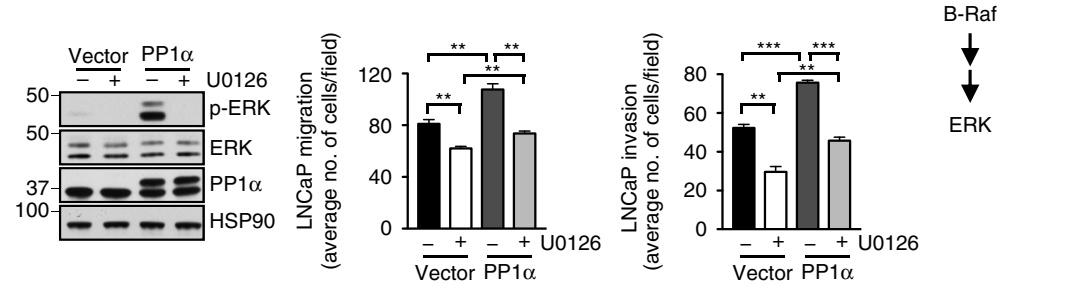

Fig. 4 PP1 $\alpha$ acts as a B-Raf activating phosphatase and promotes CaP cell invasiveness through activation of MAPK signaling. a Endogenous coimmunoprecipitation of PP1 $\alpha$ with A-Raf, B-Raf, C-Raf, MEK and ERK (the left panel) or B-Raf with PP1 $\alpha$ (the right panel) in PC3 cells. Input is $10 \%$ of total cell extracts used for immunoprecipitation. *Indicates a nonspecific band. b IB analysis of lysates from 293T cells transfected with the indicated WT or mutant Flag-B-Raf constructs plus EV or Flag-PP1 $\alpha$ for $24 \mathrm{~h}$. Quantification of p-ERK/ERK levels was carried out with ImageJ software. Numbers indicate the relative ratios to controls for phosphoprotein/total protein. Data shown are mean \pm s.e.m. of three independent experiments. $\mathbf{c}$ In vitro ERK-mediated BRaf kinase assays. Bacterial-expressed WT or mutant GST-B-Raf was purified and incubated with ERK2 in the kinase buffer with [ $\gamma^{-32 P]}$ ATP. Reaction was stopped by sample buffer and resolved by SDS-page. $\mathbf{d}$ In vitro ERK-mediated B-Raf kinase and PP1 $\alpha$ phosphatase assay. Bacterial-expressed WT or mutant GST-B-Raf was purified and incubated with ERK2 in the kinase buffer with [ $\left.\gamma^{3}{ }^{32} \mathrm{P}\right]$ ATP in the absence or presence of recombinant PP1 $\alpha$. Reaction was stopped by sample buffer and resolved by SDS-PAGE. e Representative images and quantitation of migrated and invaded LNCaP cells in the migration and invasion assay. LNCaP stable cells were subjected to migration ( $24 \mathrm{~h}$ ) or invasion assay $(48 \mathrm{~h})$ in the absence or presence of $20 \mu \mathrm{M} U 0126$. IB analysis confirmed the expression of phosphor-ERK and PP1 $\alpha$. Data shown are mean \pm s.e.m. of three independent experiments. ${ }^{\star \star} P<0.01,{ }^{\star \star \star} P<0.001$ by unpaired two-tailed $t$-test. Scale bar, $100 \mu \mathrm{m}$. f A model of the regulation of MAPK activation in PTEN-null cells by S6K, PP1 $\alpha, B-R a f$ and PML

\section{Discussion}

Integrated genetic and molecular analyses allowed us to identify an S6K/PP1 $\alpha / \mathrm{B}$-Raf pathway towards the aberrant activation of MAPK signaling. We find that this pathway is suppressed by the PML tumor suppressor through sequestration of PP1 $\alpha$ into NBs in PTEN-null cells as a result of failsafe mechanisms evoked by PTEN loss (Fig. 4f). Although the critical role of PP1- and PP2Amediated dephosphorylation in the activation of Raf kinases has previously been reported ${ }^{26,27,45,46}$, we show here for the first time that (1) PP1 $\alpha$ is amplified in metastatic human $\mathrm{CaP}$ and is the principle phosphatase positively regulating MAPK activation and that (2) S6K-mediated PP1 $\alpha$ cytoplasmic accumulation is essential for the activation of MAPK by PP1 $\alpha$. Importantly, given that PML is frequently lost in human cancer ${ }^{47}$, our study suggests that aberrant cytoplasmic retention of PP1 $\alpha$ caused by PML loss or the amplification of PPP1CA might represent a common mechanism underlying MAPK activation in cancers that lack activating mutations or gene rearrangements among MAPK signaling components, such as breast cancer and $\mathrm{CaP}^{13-17,48,49}$. Notably, since nuclear PP1 $\alpha$ has been shown to activate Rb tumor suppressor through dephosphorylation ${ }^{50}$, PML and PML-NBs do serve as rheostats to switch PP1 $\alpha$ activity from tumor suppressive to tumor promoting. It is also worth noting that although both
PML and 14-3-3 $\gamma$ interact with PP1 $\alpha$, neither of them affect PP1 $\alpha$ phosphatase activity towards dephosphorylating its respective nuclear and cytosol substrates (Supplementary Fig. 2n,o), suggesting that PML or 14-3-3 $\gamma$ primarily functions as a scaffold/ chaperone for PP1 $\alpha$ rather than as a direct regulator of PP1 $\alpha$ phosphatase activity.

Additionally, as S6K is a downstream target of the ERK pathway ${ }^{51,52}$, our study suggests that in the context of $P M L$ loss or PPP1CA amplification, the S6K/PP1 $\alpha / \mathrm{B}-$ Raf/ERK pathway represents a feed-forward loop supporting sustained ERK activation. However, we and others have previously also shown that AKT/mTOR/S6K activation triggers a negative feedback on MAPK signaling pathway, presumably as a result of the upstream IRS inactivation induced by $S 6 \mathrm{~K}^{19,53}$ (Supplementary Fig. 1). Thus, depending on the genetic context, S6K is a double-edge sword in the regulation of ERK activation, since it can act as both a suppressor of ERK activation, in the context of intact PML function, and as a promoter of sustained ERK activation, in the context of PML loss or PPP1CA amplification.

Collectively, our findings have important implications for tumorigenesis at large because simultaneous activation of MAPK and PI3K/AKT signaling undoubtedly represents a devastating force in propelling cancers into more advanced and aggressive 
diseases. Since MAPK activity can be suppressed/inhibited by small pharmacological inhibitors, this study provides a compelling rationale for investigating whether patients with co-deletion of PTEN and PML or amplification of PPP1CA may benefit significantly from combinatorial therapy targeting both AKT/mTOR and MAPK signaling that is worthy of further investigations.

\section{Methods}

Plasmids, reagents and antibodies. Human WT and c-terminal NLS ${ }^{\mathrm{c}-\mathrm{Myc}}$-tagged $^{37}$ PP1 $\alpha$ complementary DNA (cDNA) were cloned into pCMV-Tag2B vector to generate $\mathrm{PP} 1 \alpha$ expression plasmid. pCDNA3.1-hygro-B-Raf was purchased from Addgene. B-Raf and PML-I cDNA were subcloned into pGEX-4T-1 vector and used to express GST-B-Raf and GST-PML protein. All mutant constructs of B-Raf and $\mathrm{PP} 1 \alpha$ were generated using a QuickChange Lightning Site-Direct Mutagenesis (Agilent Technologies) and all mutations were confirmed by sequencing. HA-MyrAKT1/AKT2/AKT3, HA-SGK1 660 , HA-S6K1-CA and HA-14-3-3 isoforms have been previously described ${ }^{54}$. The SMART pool or two independent siRNA duplexes targeted to PML, PTEN, PP1 $\alpha$, PP2A-C, S6K1 and control non-target siRNA were purchased from Dharmacon or Sigma. The sequences for the siRNA are listed in Supplementary Table 1. The target sequences in the pLKO-PML shRNA vector against human PML were $5^{\prime}$-GTGTACGCCTTCTCCATCAAA-3' and 5'-CACCCGCAAGACCAACAACAT-3'. Tautomycin was from Enzo Life Sciences. U0126 was from Selleck Chemicals. EGF, Lipofectamine 2000, Lipofectamine RNAiMAX, RPMI, Dulbecco's modified Eagle's medium (DMEM), OptiMEM reduced serum media and fetal bovine serum (FBS) were from Invitrogen. Polybrene and puromycin were from Sigma. We used the following primary antibodies for immunoblotting: anti-p-ERK (Cell Signaling Technology, 9101, 1:1000), anti-ERK (Cell Signaling Technology, 9102, 1:1000), anti-p-MEK (Cell Signaling Technology, 9154, 1:1000), anti-MEK (Cell Signaling Technology, 9126, 1:1000), anti-A-Raf (Cell Signaling Technology, 4432, 1:1000), anti-B-Raf (Santa Cruz Biotechnology, sc-5284, 1:1000), anti-B-Raf (Santa Cruz Biotechnology, sc9002, 1:1000), anti-C-Raf (Cell Signaling Technology, 9422, 1:1000), anti-p-AKT substrate $\left(\mathrm{RXXS}^{*} / \mathrm{T}^{*}\right)$ (Cell Signaling Technology, 9614, 1:1000), anti-p-AKT (Cell Signaling Technology, 9271, 1:1000), anti-AKT (Cell Signaling Technology, 9272, 1:1000), anti-p-S6K (Cell Signaling Technology, 9234, 1:1000), anti-S6K (Cell Signaling Technology, 2708, 1:1000), anti-IRS1 (Cell Signaling Technology, 3407, 1:1000), anti-IRS2 (Cell Signaling Technology, 4502, 1:1000), anti-PP2A-C (Cell Signaling Technology, 2259, 1:1000), anti-p-CREB (Cell Signaling Technology, 9198, 1:1000), anti-GAPDH (Cell Signaling Technology, 2118, 1:6000), anti-PML (Bethyl Laboratories, A301-167A, 1:2000), anti-HA (Santa Cruz Biotechnology, sc805, 1:1000), anti-HSP90 (BD Biosciences, 610419, 1:4000, anti-PP1 $\alpha$ (Novus Biologicals, NB-110-57428, 1:1000), anti-Flag (Sigma-Aldrich, F1804, 1:4000), anti$\beta$-actin (Sigma-Aldrich, A5316, 1:4000), anti-Rb (Santa Cruz Biotechnology, sc-50, 1:1000) and anti-Lamin B1 (Abcam, ab16048, 1:1000).

Cell culture, transfection and lentivirus production. All cell lines were purchased from the American Type Culture Collection, cultured in RPMI or DMEM supplemented with $10 \%$ FBS and tested for mycoplasma contamination every month. Transfections were performed using Lipofectamine 2000 or Lipofectamine RNAiMAX reagent (Invitrogen) according to the manufacturer's instruction. In brief, $1 \times 10^{5}$ cells were transfected with $1 \mu \mathrm{g}$ of DNA plasmids or $50 \mathrm{nM}$ siRNA in a 6 well dish. Cells were recovered into completed media after $12 \mathrm{~h}$ of transfection and then harvested at the indicated times. For lentivirus production, human PP1 $\alpha$ cDNA was subcloned into the pWPI-Puro lentiviral vector to generate pWPI-PuroPP1 $\alpha$. pWPI-Puro Vector or pWPI-Puro-PP1 $\alpha(6 \mu \mathrm{g})$, pMD2.G $(1.5 \mu \mathrm{g})$ and psPAX2 $(4.5 \mu \mathrm{g})$ were co-transfected into $293 \mathrm{~T}$ cells using Lipofectamine 2000 . The virus supernatants were collected $48 \mathrm{~h}$ after transfection and filtered through a 0.45 $\mu \mathrm{m}$ filter. Freshly made virus supernatants supplemented with $4 \mu \mathrm{g} / \mathrm{ml}$ polybrene were added to exponentially growing LNCaP and PC3 cells. After $5 \mathrm{~h}$, fresh medium was added. $\mathrm{CaP}$ cells were then selected with $2 \mu \mathrm{g} / \mathrm{ml}$ puromycin (Sigma) for $48 \mathrm{~h}$ after 2-day infection and then used for the cell migration and invasion assay.

Immunofluorescence. Cells were grown on coverslips, fixed with $4 \%$ paraformaldehyde and permeabilized with ice-cold methanol. Cells were rinsed with phosphate-buffered saline, blocked with $10 \%$ goat serum and then incubated with primary antibody overnight, followed by incubation with Alexa Fluor-conjugated secondary antibodies (Life Technologies). Coverslips were mounted with ProLong Gold Antifade reagent with DAPI (Life Technologies). The following primary antibodies were used for immunofluorescence: anti-Flag (Sigma-Aldrich, F1804, 1:400), anti-HA (Santa Cruz Biotechnology, sc-805, 1:400), anti-PML (Santa Cruz Biotechnology, sc-966, 1:400) and anti-PP1 $\alpha$ (Bethyl Laboratories, A300-904A, 1:400). The stained slides were visualized by a bright-field or confocal microscope. Senescence-associated $\beta$-galactosidase activity in prostate tissue was measured with the senescence detection kit (Calbiochem) on $5 \mu \mathrm{m}$ thickness frozen section.

Western blotting and immunoprecipitation. Cell lysates or prostate tissues were prepared in RIPA buffer (Sigma) supplemented with protease (Roche) and phosphatase (Sigma) inhibitor. Proteins were separated on $4-12 \%$ Bis-Tris gradient gels
(Invitrogen), transferred to polyvinylidine difluoride membranes (Immobilon P, Millipore) and the blots were probed with the indicated antibodies. Densitometry quantification was performed with ImageJ. Nuclear/cytoplasmic fractionation was performed as previously described ${ }^{55}$. For immunoprecipitation, cells were lysed in lysis buffer ( $50 \mathrm{mM}$ Tris at $\mathrm{pH} 7.5,10 \%$ glycerol, $5 \mathrm{mM} \mathrm{MgCl}, 150 \mathrm{mM} \mathrm{NaCl}, 0.2 \%$ NP-40, protease (Roche) and phosphatase (Sigma) inhibitor) and the lysates were incubated with anti-PML (Santa Cruz Biotechnology, sc-966, 1:100) or anti-PP1o (Invitrogen, 43-8100, 1:50) or anti-B-Raf (Santa Cruz Biotechnology, sc-5284, $1: 100$ ) or anti-Rb (Santa Cruz Biotechnology, sc-102, 1:100) or anti-Flag (SigmaAldrich, F1804, 1:100) antibody overnight at $4{ }^{\circ} \mathrm{C}$. The protein $\mathrm{G}$ sepharose (GE Healthcare) was then added and incubated for another $2 \mathrm{~h}$. The immunoprecipitates were washed with wash buffer $\left(50 \mathrm{mM}\right.$ Tris at pH 7.5, $5 \mathrm{mM} \mathrm{MgCl}_{2}, 150 \mathrm{mM}$ $\mathrm{NaCl}, 0.1 \% \mathrm{NP}-40$, protease (Roche) and phosphatase (Sigma) inhibitor) three times and eluted with $2 \times$ SDS sample buffer. Prostate tissues from WT and Pten ${ }^{\text {pc }}$ $-1-$ mice as well as Primary Pten ${ }^{\text {lox/lox }}$ MEFs and their transduction with retrovirusexpressing PURO-IRES-GFP or Cre-PURO-IRES-GFP have been previously described $^{4}$. Uncropped scans for western blotting presented in main figures are provided in Supplementary Figure 3.

In vitro kinase and phosphatase assays. In vitro kinase assays were performed as previously described ${ }^{56}$. Briefly, bacterial-expressed GST-PP1 $\alpha-\mathrm{H} 248$ (the phosphatase-dead mutant to avoid the autodephosphorylation of PP1 $\alpha$ ) or GST-BRaf was purified using Glutathione Sepharose 4B (GE Healthcare) according to the manufacturer's instructions. To determine the residue(s) on PP1 $\alpha$ protein phosphorylated by S6K1, recombinant S6K1 (R\&D Systems) was incubated with $1 \mu \mathrm{g}$ of GST-PP1 $\alpha-\mathrm{H} 248$. For the in vitro phosphatase assays, recombinant ERK2 (R\&D Systems) was incubated with $1 \mu \mathrm{g}$ of GST-B-Raf in the absence or presence of PP1 $\alpha$ (Lifespan Bioscience) or PP2A-C (Abcam). Both reactions were incubated in kinase assay buffer $(50 \mathrm{mM}$ Tris- $\mathrm{HCl} \mathrm{pH} 7.5,2 \mathrm{mM} \mathrm{MgCl}$, $0.1 \mathrm{mM}$ EDTA, $2 \mathrm{mM}$ DTT, $0.1 \mathrm{mM}$ ATP) with $5 \mu \mathrm{Ci}\left[\gamma^{-32} \mathrm{P}\right]$ ATP. For PP1 $\alpha$ treatment, $1 \mathrm{mM} \mathrm{MnCl}_{2}$ was added to the kinase assay buffer to promote $\mathrm{PP} 1 \alpha$ activity. The reaction was initiated by the addition of GST-PP1 $\alpha-\mathrm{H} 248$ or GST-B-Raf in a volume of $30 \mu \mathrm{l}$ for $30 \mathrm{~min}$ at $30^{\circ} \mathrm{C}$ followed by the addition of sodium dodecyl sulfate-polyacrylamide gel electrophoresis (SDS-PAGE) sample buffer to stop the reaction before resolved by SDS-PAGE. To determine B-Raf kinase activity towards phosphorylating $\mathrm{MEK} 1$, in vitro kinase assays were performed as described previously ${ }^{57}$. Briefly, BRaf kinase was immune-purified from 293T cells transfected with Flag-B-Raf constructs. GST-MEK1 was expressed in BL21 Escherichia coli and purified using Glutathione Sepharose 4B media (GE Healthcare). B-Raf kinase was incubated with $0.2 \mu \mathrm{g}$ of GST-MEK1 in the absence or presence of PP1 $\alpha$ or PP2A-C in kinase assay buffer (10 mM HEPES pH 8.0, $10 \mathrm{mM} \mathrm{MgCl}_{2}, 1 \mathrm{mM}$ dithiothreitol, $0.1 \mathrm{mM}$ ATP). Reaction was initiated by the addition of GST-MEK1 in a volume of $30 \mu \mathrm{l}$ for 15 min at $30^{\circ} \mathrm{C}$ followed by the addition of SDS-PAGE sample buffer to stop the reaction before resolved by SDS-PAGE. Nuclear PP1 $\alpha$ phosphatase activity was determined by in vitro phosphatase assays using CREB as the substrate as described previously $^{58}$. Phosphorylated CREB protein was immune-purified from $293 \mathrm{~T}$ cells transfected with Flag-CREB. The phosphatase assay was carried out using FlagCREB and PP1 $\alpha$ in $1 \mathrm{X}$ NEBuffer for PMP supplemented with $1 \mathrm{mM} \mathrm{MnCl}{ }_{2}$ (New England Biolabs). Bacterially expressed and purified GST-PML was added as indicated in the experiments.

Cell migration and invasion assay. CaP cells stably expressing pWPI-Vector or pWPI-PP $1 \alpha$ were detached into single-cell suspension. LNCaP $\left(1 \times 10^{5}\right)$ or PC3 $\left(5 \times 10^{3}\right.$ and $5 \times 10^{4}$ for migration and invasion assay, respectively) cells in $100 \mu \mathrm{l}$ of $0.1 \%$ FBS-containing RPMI medium in the absence or presence of $20 \mu \mathrm{M}$ U0126 were placed into the top chamber of $8 \mu \mathrm{m}$ transwell inserts for migration assay or Matrigel-coated transwell inserts for invasion assay (BD Biosciences). A volume of $600 \mu \mathrm{l}$ of $10 \%$ FBS-containing RPMI in the absence or presence of $20 \mu \mathrm{M}$ U0126 were added to the bottom wells. After $24 \mathrm{~h}$ or $48 \mathrm{~h}$ (for LNCaP invasion assay only), cells on the upper surface of the inserts were removed with a cotton swab. Migrated cells were fixed in $10 \%$ formalin, then stained with $0.2 \%$ crystal violet for $10 \mathrm{~min}$. Cells were counted in four microscopic fields under $\times 20$ magnification. Results are representative of three independent experiments.

Array CGH analysis. The data were downloaded from GEO database (Grasso: GSE35988) or cBioportal (for Robinson et al. ${ }^{9}$ data set) with focus on the aCGH data sets. The $\mathrm{R}$ scripts were used to process the data. The cutoff threshold we used is -0.35 to -0.8 as heterozygous deletions, those lower than -0.8 as homozygous deletions, 0.6 to 0.8 as 1-copy gain and those higher than 0.8 as 1-copy gain.

Statistical analysis. The $2 \times 2$ contingency tables were constructed and were used to analyze categorical data (for example, copy number alteration). The data sets were compared using Fisher's exact test. For analysis of average data, data sets were compared using unpaired two-tailed Student's $t$-tests. $P$-values of $<0.05$ were considered to be statistically significant.

Data availability. The authors declare that the data supporting the findings of this study are available within the article and its Supplementary Information files. All relevant data are available from the authors upon request. 
Received: 28 November 2016 Accepted: 17 November 2017 Published online: 15 January 2018

\section{References}

1. O'Reilly, K. E. et al. mTOR inhibition induces upstream receptor tyrosine kinase signaling and activates Akt. Cancer Res. 66, 1500-1508 (2006).

2. Courtois-Cox, S. et al. A negative feedback signaling network underlies oncogene-induced senescence. Cancer Cell 10, 459-472 (2006).

3. Pratilas, C. A. et al. (V600E)BRAF is associated with disabled feedback inhibition of RAF-MEK signaling and elevated transcriptional output of the pathway. Proc. Natl. Acad. Sci. USA 106, 4519-4524 (2009).

4. Chen, Z. et al. Crucial role of p53-dependent cellular senescence in suppression of Pten-deficient tumorigenesis. Nature 436, 725-730 (2005).

5. Chandarlapaty, S. Negative feedback and adaptive resistance to the targeted therapy of cancer. Cancer Discov. 2, 311-319 (2012).

6. Siegel, R. L., Miller, K. D. \& Jemal, A. Cancer statistics, 2016. CA Cancer J. Clin. 66, 7-30 (2016).

7. Wu, J. N., Fish, K. M., Evans, C. P., Devere White, R. W. \& Dall'Era, M. A. No improvement noted in overall or cause-specific survival for men presenting with metastatic prostate cancer over a 20 -year period. Cancer 120, 818-823 (2014).

8. Grasso, C. S. et al. The mutational landscape of lethal castration-resistant prostate cancer. Nature 487, 239-243 (2012).

9. Robinson, D. et al. Integrative clinical genomics of advanced prostate cancer. Cell 161, 1215-1228 (2015).

10. Gao, H. et al. Combinatorial activities of Akt and B-Raf/Erk signaling in a mouse model of androgen-independent prostate cancer. Proc. Natl. Acad. Sci. USA 103, 14477-14482 (2006).

11. Song, M. S., Salmena, L. \& Pandolfi, P. P. The functions and regulation of the PTEN tumour suppressor. Nat. Rev. Mol. Cell Biol. 13, 283-296 (2012).

12. Barbieri, C. E. et al. Exome sequencing identifies recurrent SPOP, FOXA1 and MED12 mutations in prostate cancer. Nat. Genet. 44, 685-689 (2012).

13. Carter, B. S., Epstein, J. I. \& Isaacs, W. B. ras gene mutations in human prostate cancer. Cancer Res. 50, 6830-6832 (1990).

14. Gumerlock, P. H., Poonamallee, U. R., Meyers, F. J. \& deVere White, R. W. Activated ras alleles in human carcinoma of the prostate are rare. Cancer Res. 51, 1632-1637 (1991).

15. Moul, J. W., Friedrichs, P. A., Lance, R. S., Theune, S. M. \& Chang, E. H. Infrequent RAS oncogene mutations in human prostate cancer. Prostate 20, 327-338 (1992).

16. Palanisamy, N. et al. Rearrangements of the RAF kinase pathway in prostate cancer, gastric cancer and melanoma. Nat. Med. 16, 793-798 (2010).

17. Wang, X. S. et al. Characterization of KRAS rearrangements in metastatic prostate cancer. Cancer Discov. 1, 35-43 (2011).

18. Abate-Shen, C. \& Shen, M. M. Molecular genetics of prostate cancer. Genes Dev. 14, 2410-2434 (2000).

19. Carracedo, A. et al. Inhibition of mTORC1 leads to MAPK pathway activation through a PI3K-dependent feedback loop in human cancer. J. Clin. Invest. 118, 3065-3074 (2008).

20. Serra, V. et al. PI3K inhibition results in enhanced HER signaling and acquired ERK dependency in HER2-overexpressing breast cancer. Oncogene 30, 2547-2557 (2011)

21. Dougherty, M. K. et al. Regulation of Raf-1 by direct feedback phosphorylation. Mol. Cell 17, 215-224 (2005).

22. Ritt, D. A., Monson, D. M., Specht, S. I. \& Morrison, D. K. Impact of feedback phosphorylation and Raf heterodimerization on normal and mutant B-Raf signaling. Mol. Cell Biol. 30, 806-819 (2010).

23. Dernayka, L. et al. Autophosphorylation on S614 inhibits the activity and the transforming potential of BRAF. Cell Signal. 28, 1432-1439 (2016).

24. Guan, K. L. et al. Negative regulation of the serine/threonine kinase B-Raf by Akt. J. Biol. Chem. 275, 27354-27359 (2000).

25. Holderfield, M. et al. RAF inhibitors activate the MAPK pathway by relieving inhibitory autophosphorylation. Cancer Cell 23, 594-602 (2013).

26. Jaumot, M. \& Hancock, J. F. Protein phosphatases 1 and 2 A promote Raf- 1 activation by regulating 14-3-3 interactions. Oncogene 20, 3949-3958 (2001).

27. Abraham, D. et al. Raf-1-associated protein phosphatase $2 \mathrm{~A}$ as a positive regulator of kinase activation. J. Biol. Chem. 275, 22300-22304 (2000).

28. Mumby, M. C. \& Walter, G. Protein serine/threonine phosphatases: structure, regulation, and functions in cell growth. Physiol. Rev. 73, 673-699 (1993).

29. Paris, P. L. et al. High-resolution analysis of paraffin-embedded and formalinfixed prostate tumors using comparative genomic hybridization to genomic microarrays. Am. J. Pathol. 162, 763-770 (2003).

30. Prowatke, I. et al. Expression analysis of imbalanced genes in prostate carcinoma using tissue microarrays. Br. J. Cancer 96, 82-88 (2007).

31 Chen, M. et al. An aberrant SREBP-dependent lipogenic program promotes metastatic prostate cancer. Nat. Genet. In press (2017).
32. Junttila, M. R., Li, S. P. \& Westermarck, J. Phosphatase-mediated crosstalk between MAPK signaling pathways in the regulation of cell survival. FASEB J: 22, 954-965 (2008).

33. de Stanchina, E. et al PML is a direct p53 target that modulates p 53 effector functions. Mol. Cell 13, 523-535 (2004).

34. Scaglioni, P. P. et al. Translation-dependent mechanisms lead to PML upregulation and mediate oncogenic K-RAS-induced cellular senescence. EMBO Mol. Med. 4, 594-602 (2012).

35. Bernardi, R. \& Pandolfi, P. P. Structure, dynamics and functions of promyelocytic leukaemia nuclear bodies. Nat. Rev. Mol. Cell Biol. 8, 1006-1016 (2007).

36. Vernier, M. et al. Regulation of E2Fs and senescence by PML nuclear bodies. Genes Dev. 25, 41-50 (2011).

37. Ray, M., Tang, R., Jiang, Z. \& Rotello, V. M. Quantitative tracking of protein trafficking to the nucleus using cytosolic protein delivery by nanoparticlestabilized nanocapsules. Bioconjug. Chem. 26, 1004-1007 (2015).

38. Zhang, J., Zhang, Z., Brew, K. \& Lee, E. Y. Mutational analysis of the catalytic subunit of muscle protein phosphatase-1. Biochemistry 35, 6276-6282 (1996).

39. MacKintosh, C. \& Klumpp, S. Tautomycin from the bacterium Streptomyces verticillatus. Another potent and specific inhibitor of protein phosphatases 1 and 2A. FEBS Lett. 277, 137-140 (1990).

40. Hori, M., Magae, J., Han, Y. G., Hartshorne, D. J. \& Karaki, H. A novel protein phosphatase inhibitor, tautomycin. Eff. Smooth Muscle FEBS Lett. 285, 145-148 (1991).

41. Favre, B., Turowski, P. \& Hemmings, B. A. Differential inhibition and posttranslational modification of protein phosphatase 1 and 2A in MCF7 cells treated with calyculin-A, okadaic acid, and tautomycin. J. Biol. Chem. 272, 13856-13863 (1997).

42. Swingle, M., Ni, L. \& Honkanen, R. E. Small-molecule inhibitors of ser/thr protein phosphatases: specificity, use and common forms of abuse. Methods Mol. Biol. (Clifton, NJ) 365, 23-38 (2007).

43. Pearce, L. R., Komander, D. \& Alessi, D. R. The nuts and bolts of AGC protein kinases. Nat. Rev. Mol. Cell. Biol. 11, 9-22 (2010).

44. Baljuls, A., Mueller, T., Drexler, H. C., Hekman, M. \& Rapp, U. R. Unique Nregion determines low basal activity and limited inducibility of A-RAF kinase: the role of N-region in the evolutionary divergence of RAF kinase function in vertebrates. J. Biol. Chem. 282, 26575-26590 (2007).

45. Dhillon, A. S., Meikle, S., Yazici, Z., Eulitz, M. \& Kolch, W. Regulation of Raf-1 activation and signalling by dephosphorylation. EMBO J. 21, 64-71 (2002).

46. Strack, S. Overexpression of the protein phosphatase 2A regulatory subunit Bgamma promotes neuronal differentiation by activating the MAP kinase (MAPK) cascade. J. Biol. Chem. 277, 41525-41532 (2002).

47. Gurrieri, C. et al. Loss of the tumor suppressor PML in human cancers of multiple histologic origins. J. Natl. Cancer Inst. 96, 269-279 (2004).

48. Tilch, E. et al. Mutations in EGFR, BRAF and RAS are rare in triple-negative and basal-like breast cancers from Caucasian women. Breast Cancer Res. Treat. 143, 385-392 (2014)

49. Cancer Genome Atlas Network. Comprehensive molecular portraits of human breast tumours. Nature 490, 61-70 .

50. Castro, M. E. et al. PPP1CA contributes to the senescence program induced by oncogenic Ras. Carcinogenesis 29, 491-499 (2008).

51. Ma, L., Chen, Z., Erdjument-Bromage, H., Tempst, P. \& Pandolfi, P. P. Phosphorylation and functional inactivation of TSC2 by Erk implications for tuberous sclerosis and cancer pathogenesis. Cell 121, 179-193 (2005).

52. Roux P. P.Ballif B. A.. Anjum R.. Gygi S. P. \& Blenis J. Tumor-promoting phorbol esters and activated Ras inactivate the tuberous sclerosis tumor suppressor complex via p90 ribosomal S6 kinase.Proc. Natl. Acad. Sci.USA 101, 13489-13494 (2004).

53. Shah, O. J., Wang, Z. \& Hunter, T. Inappropriate activation of the TSC/Rheb/ $\mathrm{mTOR} / \mathrm{S} 6 \mathrm{~K}$ cassette induces IRS1/2 depletion, insulin resistance, and cell survival deficiencies. Curr. Biol. 14, 1650-1656 (2004).

54. Gao, D. et al. Phosphorylation by Akt1 promotes cytoplasmic localization of Skp2 and impairs APCCdh1-mediated Skp2 destruction. Nat. Cell Biol. 11, 397-408 (2009).

55. Trotman, L. C. et al. Ubiquitination regulates PTEN nuclear import and tumor suppression. Cell 128, 141-156 (2007).

56. Rushworth, L. K., Hindley, A. D., O'Neill, E. \& Kolch, W. Regulation and role of Raf-1/B-Raf heterodimerization. Mol. Cell. Biol. 26, 2262-2272 (2006).

57. Wan, L. et al. The APC/C E3 ligase complex activator FZR1 restricts BRAF oncogenic function. Cancer Discov. 7, 424-441 (2017).

58. Hagiwara, M. et al. Transcriptional attenuation following cAMP induction requires PP-1-mediated dephosphorylation of CREB. Cell 70, 105-113 (1992).

\section{Acknowledgements}

We thank all the members of the Pandolfi lab for critical comments, and Lauren Southwood and Elizabeth Stack for editing the manuscript. We thank the BIDMC Confocal Imaging Core facility. M.C. was supported in part by the DOD Prostate Cancer 
Research Program (PCRP) Postdoctoral Training Award. This work was supported by NIH grants R01CA-142780, R01CA-142874 and R35CA-197529 to P.P.P.

\section{Author contributions}

M.C., L.W., J.F.Z., K.B., J.V., Q.Y. and Y.Z. performed the experiments. M.C., L.W., W. W. and P.P.P. conceived and designed the experiments. W.W. and P.P.P. supervised the study. J.W.Z. performed all bioinformatic analyses. M.C., L.W., J.W.Z., W.W. and P.P.P. analyzed the data. M.C., L.W., L.M., J.G.C., W.W. and P.P.P. wrote the manuscript. All authors critically discussed the results and the manuscript.

\section{Additional information}

Supplementary Information accompanies this paper at https://doi.org/10.1038/s41467017-02272-y.

Competing interests: The authors declare no competing financial interests.

Reprints and permission information is available online at http://npg.nature.com/ reprintsandpermissions/
Publisher's note: Springer Nature remains neutral with regard to jurisdictional claims in published maps and institutional affiliations.

(c) (i) Open Access This article is licensed under a Creative Commons Attribution 4.0 International License, which permits use, sharing, adaptation, distribution and reproduction in any medium or format, as long as you give appropriate credit to the original author(s) and the source, provide a link to the Creative Commons license, and indicate if changes were made. The images or other third party material in this article are included in the article's Creative Commons license, unless indicated otherwise in a credit line to the material. If material is not included in the article's Creative Commons license and your intended use is not permitted by statutory regulation or exceeds the permitted use, you will need to obtain permission directly from the copyright holder. To view a copy of this license, visit http://creativecommons.org/ licenses/by/4.0/.

(c) The Author(s) 2018 